\title{
Prostorne modulacije i dezeni materija
}

\author{
Prilozi za tumačenje poezije Janoša Siverija
}

\author{
ZOLTÁN VIRÁG \\ SZTE BTK Magyar Irodalmi Tanszék, H-6722 Szeged, Egyetem u. 2. \\ E-mail: viragz@hung.u-szeged.hu
}

(Received: 14 June 2019; accepted: 3 October 2019)

Biće da je tokom svojih slikarskih studija i realizacije vlastitih zamisli iz oblasti primenjene grafike Janoš Siveri prvi put obratio pažnju na usklađenost i zajedničko dejstvo, kao i na efekat spontane mehanike i formalnih varijacija koje pruža skupolika posloženost tela. On je u svojim tekstovima na temu umetnosti više puta pisao o suštini audiovizuelne i skriptovizuelne informativnosti. Posebno se, već na samom početku svog pesničkog puta, zainteresovao za teorije sistema prirodnih i veštačkih sredina, za smerove kretanja, za mogućnosti rukovanja raspodelom energije, ali i za perspektive izvlačenja linija kao takvih. Dinamizam gradivnih materijala prostora, spremnost na udaljavanje od dubinskih distanci, za otklon od graničnih tačaka raznih objekata, javlja se kod njega u drugoj polovini 1970-ih godina.

Dominantni postupci stvaranja ovakvog odnosa ovaplotili su se kroz rađanje paralelnih nizova, dočaravanje pejzaža $u$ asocijativnom rasplitanju grupacije boja i materije, odnosno u funkcionalnoj analizi materijalnog prostiranja jezičkih znakova. Jedan od najkarakterističnijih idejnih stubova njegovog eseja Sloboda miljea (Beleške o virtuelnoj kulturi) na temu filozofije umetnosti, glasi ovako: „Vizuelne informacije sručuju se na nas u ogromnim količinama. Svaki je predmet na izvestan način medijum za prenošenje poruke, čak i u onim slučajevima kada te skrivene informacije ne uspevamo da (na odgovorajući način) dekodiramo" (SzIVERI 2011: 345 ). Kao da se kroz ovaj pristup koji aludira na kohezionu kosmologiju predmetnih odnosa provlače osnovne crte pogleda koji je izložio u svojoj debitantskoj zbirci pesama pod naslovom Slobodne vežbe [Szabad gyakorlatok, 1977]. Savremena kritika nije, međutim, bila preterano prijemčiva za lirski svet rečene zbirke, zasnovan na korpuskularnoj poetici, nije imala sluha za njenu minucioznu analizu koja prodire sve do molekularnih struktura, do atomskih permutacija. Ni ciklična raspoređenost tekstova u pomenutoj zbirci, a ni njene, poput lijana razgranate rečenice nisu naišli na nepodeljeno odobravanje kritike. Premda bi se o iluminativnoj prirodi, o geometrijskoj kompatibilnosti, ali i o međuzavisnosti ispunjivih postora i telesa moglo reći gotovo isto što i o onome što se iskristalisalo u zbirci Vavilon [Bábel, 1990] koju je još on sam sastavio, ali koja je objavljena tek nakon njegove smrti: „Materijalno predstavljanje čulnih i emotivnih iskustava, plastične projekcije osećaja i slutnji, pukotina svesti i misaonih procesa, njihovo projektovanje 
u pejzaž, u predmet, u fenomen, u boju i svetlost, svedočanstva su majstorske kompleksnosti" (Тномка 1993: 123-124).

U jezičkoj drami u kojoj subjekt ne pronalazi svoj objekat, nalazimo ulančavanje istovremeno postojećih i imaginarnih poprišta (upor. CsORBA 1995: 22). Pesnički govor ne samo što je čvrsto vezan za spoljašnje draži, već egzistira u simboličkoj zajednici sa njima (upor. ZALÁN 2000: 133). On permanentno reflektira na određene tekstove, na cikličnu ustrojenost i na samu konstrukciju zbirke, ne bi li evidentirao odnose rubnosti i integracione središnjice, ne bi li osvetlio njihove semantičke ekvivalencije. Kroz kartografsko prikazivanje elemenata njihovog upregnutog univerzuma, on te elemente, njihove konstelacije i nivoe, jedan po jedan arhivira. Kroz vibraciju oblika i formalnih vezivanja ,alegorijsko-geometrijskog sistema slika" (LÁBADI 2008: 51) koji čine zatvoreni uglovi sastavljeni od lopti i populopti, od valjaka, od isečaka krugova i od kocki, naslućuju se zamisli jednog atomizma koji računa na ekonomiku elementarnih čestica kao na matematičke tačke bez prostiranja ili kao na čiste centre sile.

Ova eruditivnost koja se hrani orfičkim misterijama, epikurejskom filozofijom i mnoštvom motiva iz filozofske poeme $O$ prirodi stvari [De rerum natura] Tita Lukrecija Kara, ujedno u prvi plan stavlja i logičke zamke, sadržinske napetosti, tautologije i paradokse izazvane činjenicom nakrivljenja tela izazvanih dejstvom drugih tela na njih, njjhovim promenama, onome što nazivamo clinamen. U ovim pesmama se, bez ikakvih morfoloških i integrativnih ograničenja, pojavljuju apstraktne forme i izmetnute površi uhvaćene u svoj fluidnosti njihove čvrstine i zapremine, sa svim svojim perifernim šarama i deyenima. Suština geometrijskog aktivizma lirskog subjekta ne leži dakle u stvarnoj primenljivosti uobičajenih i poznatih geometrija, ona se ne nalazi u njihovom odnosu prema svetu, u njihovom proglašavanju za autentične i lažne, već u konstrukciji definitivnih analogija i zadovoljavajućih teorema, sastavljenoj od čisto analitičkih tvrđenja. „On polazi od jednog neoavangardnog konceptualističkog pristupa u čijem je središtu vizualizacija sveta stvari, geometrijsko predstavljanje predmeta, njihovo rastavljanje na sastavne delove, te sastavljanje tih delova na drugačiji, novi način. Hiperrealistično posmatranje sveta koji funkcioniše i bez nas. On se ovom suštinski grotesknom tehnikom oneobičavanja služi mahom u znaku vizuelnog" (CsÁNYI 2010: 51-52).

Janoš Siveri nikada nije krio da postoji produktivni dijalog između njegove poezije i lirike Vaska Pope. Origo tog intimnog pesničkog srodstva nesumnjivo su Slobodne vežbe, premda vektori uticaja sežu sve do druge njegove posthumne zbirke Privatni plac [Magánterület, 1990]. Na putu koji vodi od opstanka na tankoj kori života do spoznaje o leksikalnoj nezamenljivosti maternjeg jezika skrojenog po ličnoj meri, telo služi kao navigaciono sredstvo, ono postaje kompas, a ,predodžbe vezane za njegovo funkcionisanje organizuju se u sistem, te na taj način najzad ostvaruju mitopoetičku ulogu u obe pesničke imaginacije" (CsÁNYI 2010: 55). A odista nije teško naći harmonična saglasja, zasnovana na izražavanju bioloških limitacija i taktilnih senzacija, između Popinih planiranih zbirki i pesničkih ciklusa posvećenih dekompoziciji i rekompoziciji različitih materijala i ostataka materijala s jedne, i Siverijevih tekstualnih serija, s druge strane. Fokusiranost sa 
tela na telo, usredsređenost na procese selidbe iz jednog tela u drugo, divljanje prenošenja draži i iživljavanja nagona, posredovano je najviše govorom kroz prvo lice jednine ili množine. Površinske mazotine, tkanja, izrasline, fosili, šupljine, otvori, nabori i njihovo sortiranje, odnosno korporalni repertoari žila, kostiju i krvi, ponuda njihovih slika u krupnom planu, zapravo predstavljaju koreografiju za obrede u kojima sećanje zapravo nastoji da izbledi auru umetnosti. Sve je to legitimacija ranjivog, ružnog, propadljivog, drugim rečima, biološke projekcije ,gomilanja skrpljenog”, „ništavnih iskopina”, „kontuzija predmeta”, „zapomaganja boleština”, „creva vaseljene u fazi pražnjenja” i ,vozikanja na cesti smrti”. Takav primer nalazimo u naslovnoj pesničkoj celini Slobodnih vežbi, pa u egzistencijalnim interpretacijama Hladne probe [Hidegpróba, 1981], posebno u pesmama Kakvi materijali [Miféle anyagok] i Nove nepoznate [Új ismeretlenek], zatim u gotovo televizijski estradizovanim dosetkama iz zbirke Dija-pesme [Dia-dalok, 1987], naročito u pesmama Drvena kolevka iz Panonije [Pannon fateknő] i Javna balada o stvarnosti [Közérdekü ballada a valóságról], a pogotovo se ta tendencija iskristalisala u prvoj njegovoj pesničkog zbirci objavljenoj na tlu Mađarske, pod naslovom Utuvljivanje [Szájbarágás, 1988], a naročito u majstorskim invektivama političkih pesama Organizator se ovaploćuje [A Szervező testet ölt] i Pesma traktoriste [Traktoros vers].

Životne okolnosti koje nadilaze instrumentalnu namenu i podražavalačku egzistenciju, kao i refleksi popinskog jezičkog skladištenja berbe predmeta, pojavljuju se ponovo, sa pojačanim kreativnim potencijalom fiksiranosti i mobilnosti, u opisima prizora zbirki Janoša Siverija. Kružna struktura dela srpskog autora rumunskog porekla, antipoetika, apsurdna geneza, čulne intenzifikacije, jezička hodočašća i etimološka askeza zbirki poput Kore (1953), Nepočin-polja (1956), Sporednog neba (1968) ili Uspravne zemlje (1972) na taj način našla je dostojnog nastavljača u delima ovog mađarskog pesnika iz Vojvodine. Spektri oblikovanja i promenljivosti, dimenzije zamenljivosti značenja i konteksta, našli su mesto u poeziji ove dvojice pesnika kroz proširenje autonomije ništavnih stvari, mikroskopskih elemenata, banalnih predmeta, kroz narušavanje njihovog funkcionalizovanog identiteta. I baš kao što samostalni i neosvojivi, nepokorni (upor. Petrović 1995: 61) kamičak, kvarc, daje kamenu oblik, pruža mu figuralnu strogoću, i baš kao što kost koja izbija iz mesa i ostaje za telom, ima perfektan oblik kod Vaska Pope, isto tako pomorandža kod Janoša Siverija poprima osobene karakterne crte i ontološku relevanciju. Ona poseduje vremenitost i sudbinu, javljaju se njene varijante, o čijim kvalitetima on referiše, sa neznatnim modifikacijama, citirajući prevod Šandora Vereša (PoPA 1968: 51) u monogramskom zatvaranju Slobodnih vežbi u pesmi Događanje narandže [A narancs történik]: „Belutak je kadar za / mnogo sićušnih narandži, ali / nije ovde igra važna / »Svud okolo (ono) ništa« (V. P.)". „Kamen ko kamen” - čitamo pesmu Vaska Pope prizvanu u dijalog, u drugom stihu Vereševe verzije Popine pesme Srce belutka (PopA 1968: 50), ${ }^{1}$ na koju već naslovom Narandža je narandža [A narancs narancs] reflektira peti deo ciklusa

\footnotetext{
${ }^{1}$ Sentenciju iz originalnog teksta manje je uspešno („Poput nekakvog kamena” / „Mint afféle kő") preveo Károly Ács u svojoj verziji (upor. PoPA 1963:219).
} 
Janoša Siverija. Polivalentne manifestacije kostiju i belutka, njihov antropomorfni i zoomorfni kosmos, zgušnjava u sebe, sjedinjuje univerzum kugle, to jest narandže shvaćene kao opšti pojam kruga.

Iz heroizma i perfekcionizma formiranja, a potom i dekonstruisanja neposredne okoline, kao i iz simboličkog potencijala petrifikacije, ogoljavanja na anatomsku strukturu skeleta, metamorfoze u voćno vlakno, te portreti narandži proizašli iz toga, demonstriraju samo-događanje pesničkog predmeta, tu težnju sa snagom egzistencijalnog saopštenja, u kojem bi narandža bila određenje narandže, tog umetničkog dela po sebi, tog večnog savršenstva. O značajnom delu tekstova iz debitantske zbirke zaista bi se moglo reći da „su napisani prema pravilima igre jednog samosvojnog poetičkog univerzuma, koji je sačinila pasivna, meditativna svest" (Losoncz 1988: 208). Śtaviše, upravo iskustvo pigmentacije tog spekulativnog prostora, permanentno obigravanje oko njegovih modaliteta, služi kao jemstvo pogleda u tragično ogledalo individualne mitologizacije, budući da nas suočava sa agonijom fragmentarne ukomponovanosti. Biljna i mineralna egzistencijalna stanja, procesi prirodne selekcije i varijeteti razvoja jedinki, teku paralelno sa mutacijom tela od krvi i mesa, sa njihovom de-evolucijom. Fond jezičkih sredstava kojem se pribegava zarad opisivanja grupacije fenomena, permanentno je izložen eroziji pojmova, sklerozi reči koja ga sve vreme razara i rasparčava. Svaka od pesama iz Slobodnih vežbi ,predstavlja otiskivanje iz jednog drugačijeg ugla, geometrijsku projekciju, opsada jedne te iste misterije uz pomoć nekog elementa sveta" (CSÁNYI 2010: 31).

Književni predznaci, zajednički izvori i motivi čija je suština u kontrastu između kretanja i nepomičnosti, u naglašavanju senzoralnih aspekata makroraspodele i mikrometara, u forsiranju apstraktnih asocijacija, nadrealnih vizija, te interakcija fragmentarnih prostiranja, mogu se prepoznati u umetnosti Fransisa Ponža. Gotovo sve što je rečeno o vodi, o fauni i flori, o smeni godišnjih doba, o moru, školjkama, puževima, oblucima, kostima i narandžama u ciklusu proznih pesama pod naslovom Le parti pris des choses [Pristrasnost stvari / Na strani stvari, 1942], dolazi do izražaja u delima Vaska Pope, tog pesnika sa sjajnim obrazovanjem iz svetske književnosti, a posledično, pod Popinim nesumnjivim uticajem, i u poeziji Janoša Siverija. Fransiz Ponž je u prividnoj nepredvidivosti i nerazumljivosti poznatih formi i predmeta (upor. BROwN 2004: 6) otkrio merodavnu osobinu kamena projektovanog da bude skelet Zemlje, parče stene otkinuto sa jedinog zajedničkog pretka, sa mitskog tela: „budući da se kamen u prirodi ne stvara ponovo, u tom smislu on predstavlja jedinu stvar koju odlikuje permanentna prolaznost" (PONGE 2005: 804-805). U procesualnoj poeziji koja nudi meditacije imenovanja (o tome videti SCHWENGER 2004: 142-146), u segmentaciji života kamena, upravo ,belutak predstavlja ono doba kada njegova ličnost, njegovo Ja počinje da se stvara, to jest doba govora" (Ponge 2005: 805). Egzistencijalna orijentacija kvarcnog kristala, belutka Vaska Pope, razgranava se upravo u ovakvim fazama, „kao svet između svetova” (San belutka), u srećnom grču ,sam sa sobom” (Tajna belutka) on ispunjava i ostvaruje, citirajući dakako i Mit o sizifu Albera Kamija, „vlastiti teret u sebi samom" (Pustolovina belutka). 
Narandža Fransisa Ponža predstavlja derivat koncentrovane materije koja izaziva prozopopejske strategije, kompaktnu i sunđerastu pilulu čija se pasivnost lako može iskoristiti pri totalnoj upotrebi ili likvidaciji objekta / umetničkog dela / trgovinskog artikla (upor. NGAI 2005: 832). Hrapave površine epiderma, agrumolika jarkost njihovih boja, te njihov unutrašnji lavirint koji provocira klijanje, prenos sokova, njihova mreža žilica i kolonija semenki, bacaju svetlo na „sasvim malecki, ali pouzdan razlog postojanja" (PONGE 2005: 786) ove sićušne kugle. Pomorandžinska arhitektura Janoša Siverija, proizašla iz kičmenog stuba, delova pršljena, patrljaka rebara, komadića kostiju, jedara desni, grozdova rđe, oklopa insekata, krljušti, zrnaca peska, staklenih eksera, veoma je bliska francuskom autoru. Istovremeno se može smatrati prirodnom formacijom, ali i objektom kao realizacijom pesničkih opsena. A opet, ona nije nužno plod metaforizacije, više se pojavljuje „kao apsolutni kod” (CsÁNYI 2010: 31), kao kvintesencija međuzavisnosti.

Patologizujuće fiksiranje prizora u privatnoj lirskoj znakovnoj strukturi Slobodnih vežbi, oličeno u tkanjima, čvorovima, ugibanjima, bujanju ćelija i nervnih čvorišta, odnosno prostorne relacije i regulisanje kretanja ostataka kostiju, nataloženog kreča, mrlja, pejzažnih gravura, posle jedne tačke postala je neizvodljiva. Polazeći od bljesaka fantazije i opažajnih pražnjenja, lirski govornik se otisnuo u napipavanje vlastitog carstva, uzdigavši komfor svoje pustinje na visoki nivo. Svaki put je, međutim, završavao u vučjim jamama svoje mašte, budući da su pomeranja u razmerama prividnih perspektiva, kao i razlike u akcentuaciji, potresli njegov izveštačeni univerzum. Kako je u osnovnom tonu naslovnog ciklusa već nagovešteno, zbirke objavljivane u narednim decenijama donose zreliji i ujednačeniji modalitet u kojem se mnogo oštrije ističu ambivalencije teritorijalne pogođenosti, vernosti istorijskim tradicijama, ideološkog drila i generacijskih interesnih grupa: ,Svi na istoj stranputici. Svi / iz iste zajednice i u istoj zajednici. / Raštrkani po najčistijem mogućem pejzažu / najčistije moguće" (Jedan glas [Egy hang]).

Pesme iz zbirki Hladna proba, Dija-pesme, Utuvljivanje, a zatim u njihovom nastavku u knjizi Kojim dobrom? [Mi szél hozott?, 1989] ciljaju šeme represivnih scenarija koji pritiskaju društva jugoistočne Evrope, kao i lažnu kolektivnu svest koja se guši u opštim mestima. Ovo pesničko profinjenje koda i bogaćenje rečnika, moglo bi se kazati, povoljno utiče na njegovu poeziju, budući da kroz treptaje smisla, kroz proklizavanja značenjskih momenata i njihovo izvrtanje, proširuje pesnički teren Slobodnih vežbi sa očito suženih i ograničenih horizonata na sociokulturne jedinice. Ogoljenost kostiju, isušenost, raspadanje, metamorfoze unutrašnjosti tela i spoljašnjeg pokrivača ili pak njihove situacione rokade evociraju prethodno pomenute zbirke Vaska Pope. Tretiranje objekata, razvijanje teme i slojevitost glosara u njegovim ciklusima Opsednuta vedrina, Belutak, Ćele-kula, Vrati mi moje krpice, Oči Sutjeske, Kost kosti, ne samo što su se produktivno uvukli u saznajne skale Hladne probe, Dija-pesama i Utuvljivanja, već se u dobroj meri prepoznaju i u minuciozno sastavljenim bezinterpunkcijskim strukturama zbirke Kojim dobrom? (npr. u pesmama Jedva išta, Ne bojimo se vuka, Junaci sutrašnjice, Šetnja kroz bronzanu šumu), te u masivnim lirskim blokovima Vavilona (npr. u pesmama U znaku ovna, Ah, Demonion, Kuda truliš?, Civitas dei, Čišćenje sa 
masnom sodom, Visimo na utegnutom konopcu, Vavilon), a najzad i u pesničkoj praksi zbirke Privatno vlasnišstvo, koja niveliše i za sobom ostavlja istaknute momente (npr. u pesmama Slike u pesku, Druga obala, Zubima i noktima).

Pesma Predskazanja [Próféciák] iz zbirke Dija-pesme odmah otvara dijalog sa čak dve Popine lirske tvorevine. Sušenje profetske telesne presvlake koja kao da priziva sudbinske obrasce i životne puteve Janusa Panonijusa i Endrea Adija („Ne »goji se« meso na meni, / koža mi se suši na bubnju. / I jezik jedva natucam / i trpim”) nedvosmisleno aludira na „kožu nategnutu na bubanj” iz Zlatnog bremena. Prinudna egzistencijalna situacija stešnjenosti među zidove koji podsećaju na tamničke („Do zida, na zidu, / i od zida do zida: obrazac. / Zastajem. / Sa srcem belutka u toj teleološkoj zimi”) pak analogni su sa iskustvom koncentracionog logora koje je srpski stvaralac imao u nemačkom zarobljeništvu. On je evocirao dramu totalne, elementarne onemogućenosti življenja života (upor. ANTONIJEvić 1996: 336-337) u minijaturi pod naslovom Zid u okviru teksta Sećanje za Bečkerečki zatvor 1943, a na stranicama zbirke Kuća nasred druma (1975): „Oči u oči sa zidom // Nisam ni lep ni ružan / Lica nemam [...] Ovde sam bez srca // Pred zidom/ I ja postajem zid" (PopA 1997: 371).

U egzistencijalnoj panorami Janoša Siverija, višestruko isprepletanoj sa onom Vaska Pope, tela upotrebljiva u svrhu samostalnih veština, $u$ interesu vlastitih artističkih izvedbi, u cilju zadovoljenja njihove praktične svrhe, istovremeno su potrošni artikli, ali i ponizne sluge gorko-slatkog vojvođanskog baroka seratora i posranih, njihovog farisejskog medijskog populizma. Ova tendencija pojačala se negde u vreme pisanja Hladne probe, ona je, štaviše, primetna i u neizdatim pesmama i njihovim varijantama. „Subjekat gubi sigurnost koju je, izgleda, nalazio u kosmičkom ozračju svojih pesama; metafizika je zamenjena bezdomnošću personalnosti, refleksivnošću koja nosi breme sumnje" (Losoncz 1988: 210). Alternacija „Pukotine” - mislim [„Rés”- gondolom] datirana na maj-avgust 1979. godine upravo u ovom duhu reaguje na aktuelno-politički horizont: ,Ja neću nas predati, poreći, / već premeriti prekrasnu tamnicu naših kostiju: / Meso, to navodno važno propisivanje". ${ }^{2}$ Pesma Strogo poverljivo [Szigorúan bizalmas] objavljena u martovskom broju novosadskog časopisa Hid za 1981. godinu, daje fijasku uzvišenja plastičnosti tela, jedno dostojanstvo obrazovnog i pedagoškog modela: „Gle: visim na paukovoj mreži tu-bitka. / I kao žile na kvrgavom listu / tako i mene premrežuju nametnute zakonske / slučajnosti. I moje / te / lo / razliva se svetom". (Op)scenacija naknadnog dejstva gubitka istorijskih iluzija i društvenih kriza, pokazala se u vagabundskoj ritmičnosti stilskih minimaliteta u frivolnim stihovima zbirke Bežanija Tibora Z. [Zalán T. Futása] koja je ostala u rukopisu: „Dlake rastu! Danas je / subota pičke. / Doći će pop / iz Rimavašara. / I istrešće vrpcom svezane / kletve". ${ }^{3}$ Duža, dvodelna varijanta ciklusa Popravljanje praznika [Ünnepjavító,

\footnotetext{
${ }^{2}$ Ovaj tekst je posredstvom Lasla Fizija objavljen u majskom broju časopisa Forrás za 2002. godinu, na str. 32 .

${ }^{3}$ Strofe, najverovatnije napisane početkom 1980-ih godina, nedavno su, uz komentare pomenutog kolege pesnika, Tibora Zalana objavljene u onlajn-časopisu Irodalmi Jelen Online.
} 
1985] usudila se da istorijama manjinskog patništva i traženja opravdanja suprotstavi obrnutu logistiku književnog preživljavanja i perspektive: ,u kakvom to jezičkom silosu živim / unazad u vremenu / i posmatram / neverne leševe // na svakom koraku / njih gledam / zaviruju mi u glavu / tandrkava mrtva telesa". ${ }^{4}$

Autora Dija-pesama, koji ismeva narative industrije želja i medijske rituale „,ne zanimaju metafizičke i neopipljive implikacije postojanja i stvarnosti, već njegove višestruko uočljive, čulima dosegljive draži” (THOMKA 1987: 91), među kojima se posebno ističe stilska smotra, mustra publike i razotkrivanje balkanske socio-vurstle u ciklusu Kojim dobrom?, koje izvodi kroz iznošenje generacijske podele uloga, univerzalizama stranosti i (samo)zapitanosti nad aktima oneobičavajuće diferencijacije: ,razdvaja nas planina štampe / poput bratstva i jedinstva - // [...] i makar bio psoglavi Tatarin, Jermenin / ne opravdava me zakon o štampi, tiranin" (Informnacija [Informnáció]). Svemu tome se u Vavilonu i Privatnom vlasništvu pridružuje topografska scenografija i etnička mozaičnost koja čini da se prostorne kriške omeđene Dunavom, Tisom i Begejom, kroz ruralne detalje, stambene ambijente $\mathrm{i}$ geospecifične samoidentitete, međusobno privlače. Time se on ujedno vraća praksi pozajmljivanja lica i katalogizacije imena koje smo i u prošlosti često nalazili kod autora panonskog zavičaja i panonskih kompetencija, poput Janusa Panonijusa, Petera Bornemise, Mihalja Verešmartija, Dežea Kostolanjija, Atile Jožefa, Janoša Pilinskog, Lajoša Grendela, Tibora Zalana i drugih, koje Siverijeva poezija evocira.

Ranjene, raskrvavljene kulise ovog predela, njegove ,konture koje počinju da trule" (Civitas dei) organizuju se u geobiografske identitetske znake, pretvaraju se $\mathrm{u}$ organske analogije. Fizionomijska kompleksnost prostora prirode obučenog u masku ,večito gladnog strašila" (Doba riba [Halak kora]), potpomognuta analizom nacionalne situacije u stihovima ,visimo na napetom užetu / sve sami hibridni stranci" (Visimo na napetom užetu [Lógunk feszes zsinegen]) poprima tamnije tonove. Konkluzije propadljivosti tela koje se suši kao kožni omotač vlastitog skeleta, računajući na krize njegovih organa, na njegovu zdravstvenu neodrživost, sumira jedna koherentna ličnost, kao neizvesnu životnu perspektivu: ,Ja sam Dunav i karlična kost / sićušni mrazevi na mom osušenom jeziku / dve trećine mog želuca odneo je Dunav / hoću li više ikada samim sobom gospodariti?" (Karlična kost Dinavskog basena [Dunamedencecsont]). Ovaj tematski krug poznat je, još lišen svesti o bolesti, iz Slobodnih vežbi, te u fragmentu koji počinje rečima Pre mnogo godina... [Évekkel ezelőtt...], gde još figurira kao „,karlična kost teksta, njegove sklerotične naslage". Tu se Janoš Siveri po svemu sudeći obraća metaforici i simboličkom arsenalu slike rebara neba i ,kukova oluje” kod Vaska Pope, multifacijalnosti proistekloj iz nevolja koje uzrokuju prolaznost i preokreti sudbine (upor. ANTONIJEVIĆ 1996: 80), aludirajući na početni deo ciklusa Kost kosti pod naslovom Na početku. Njegove egzistencijalne kalkulacije, inventarisanje delova tela, mogli bismo nazvati percepcionim panonizmom subjekta koji opaža i minuciozno beleži

\footnotetext{
${ }^{4}$ Veliku zahvalnost dugujem Beati Tomka, koja mi je stavila na raspolaganje rukopis njoj posvećene pesme.
} 
neposredne utiske, no možemo ga nazvati i interakcijskim panonizmom stalnog pripajanja i razdvajanja, antropomorfizacije sa ciljem stvaranja humanog tela, na granici organski izgrađenog individuuma i biologije prostora (više o tome: JuKIĆREM 2012: 449-450).

U atomistički inspirisanoj kosmografiji skretanja, zaobilaženja, sporednog koloseka formi i agresivnih predmeta, nema zapravo suštinske razlike između zatvorenih vrtloga sudaranja materije, njenog pozicionog prilagođavanja, usložnjavanja značenja prisutnog u Slobodnim vežbama s jedne, te radikalne geometrije Privatne svojine u kojoj se iskričavo sudaraju prošlost i sadašnjost, s druge strane. Držanje za premise afirmacije bitka, odbrana zasnovana na sporednim iskustvima pejzaža i zavičaja, kao da kod Janoša Siverija apriori predstavljaju oslobađajuću tehniku sklanjanja, mimikrije, skrivanja. „Subjekt je u središtu ovosvetske drame. Između deziluzija biološke propadljivosti, pada utopija i transcendentnih uporišta i ljudskog sveta koji nije zasnovan na vrednostima dobra, nalazi se subjekt sa svojim razorenim mitovima identiteta, podrivene moći pesničkog jezika, evokativne geografije porekla koja se izručuje poput nesastavljivih krhotina, moći i zla koji oblikuju provizorij scene društvenosti" (ZIVLAK 2005: 49). U pat-poziciji pokrajinskog suživota kao zvaničnog propagatora homogenosti, u njegovim institucionalnim okvirima koji podstiču razdore, osuđenost na izgnanstvo, na pad i prolaznost, iscrtava se kao smrtno sigurna kondicioniranost života, a „kao jedina evidencija nameće se spoznaja da u ovoj igri geometrije naše mesto odgovara mestu propadljive, zrnaste materije" (ТномкA 1993: 141). Stav koji sa prezirom odbacuje svaku vrstu saginjanja, koji ponosno stresa sa sebe prinudne regionalne neuroze, polifoniju koja ismeva manjinske melodrame, tu telesnu i duhovnu vavilonizaciju uspeo je da oplemeni i uzdigne na nivo autentičnih saveta, pesničkog creda tek pod senkom rušenja i propadanja: ,Za života traćim sebe, / nizašta, nizakog ne hajem. / Rođen u znaku Jarca, / rastem i kada nestajem" (U znaku Jarca) (SIVERI 2005: 10). ${ }^{5}$

\section{Preveo sa mađarskog Marko Čudić}

\section{Literatura}

AntoniJević 1996 = AntoniJević Damnjan: Mit i stvarnost. Poezija Vaska Pope. Beograd: Prosveta, 1996.

BRown 2004 = BRown Bill: Thing Theory. In: Brown Bill (ed.): Things. Chicago-London: The University of Chicago Press, 2004. 1-16.

CSÁNYI 2010 = CsÁNYI Erzsébet: Lírai szövegmezök. Vajdasági magyar versterek, kultúraközi kontextusok / Lirski konteksti. Vojvođanski mađarski pesnički prostori, interkulturalna polja. Újvidék / Novi Sad: Vajdasági Magyar Tudományos és Művészeti Akadémia / Vojvođanska akademija nauka i umetnosti, 2010.

CsORBA 1995 = CsORBA Béla: Akár ha szélben ezüstöt reszelnél (Sziveri János: Szájbarágás). In: CsorBa Béla: Ceruza vagy cenzúra. Publicisztikai irások. Budapest: Hatodik Síp Alapítvány, 1995. 22-24.

\footnotetext{
${ }^{5}$ Na mađarskom: „Tékozlom magam élveteg, / de senki lábához nem rogyok. / Születtem a Kos jegyében, / s gyarapodom - bár elfogyok".
} 
JukiĆ-Rem 2012 = Jukić Sanja, Rem Goran: Panonizam hrvatskoga pjesništva I. Budimpešta: Filozofski Fakultet Univerziteta Eötvösa Loránda u Budimpešti, Osijek: Filozofski fakultet u Osijeku, 2012.

LÁBADI 2008 = LÁBADI Zsombor: A lebegés iróniája. Sziveri-szinopszis. Újvidék: Vajdasági Magyar Felsőoktatási Kollégium, 2008.

LosonCz 1988 = Losoncz Alpár: Anti-poétika mint kiút (Sziveri János: Hidegpróba). In: Losoncz Alpár: Hiányvonatkozások. Társadalomfilozófiai témák. Újvidék: Fórum, 1988. 206-214.

NGaI 2005 = NGaI Sianne: The Cuteness of the Avant-Garde. Critical Inquiry 31 (2005): $811-847$.

Petrović 1995 = Petrović Miodrag: Univerzum Vaska Pope. Niš: Prosveta, 1995.

Ponge 2005 = Ponge Francis: A dolgok elfogultsága. Nagyvilág 2005/10: 783-807.

Popa 1963 = Popa Vasko: Kéreg. Novi Sad: Forum, 1963.

POPA 1968 = POPA Vasko: Ostromlott derü. Budapest: Európa, 1968.

PopA 1997 = PopA Vasko: Sabrane pesme. Vršac: Društvo Vršac lepa varoš, 1997.

Schwenger 2004 = Schwenger Peter: Words and the Murder of the Thing. In: Brown Bill (ed.): Things. Chicago-London: The University of Chicago Press, 2004. 135-151.

SIVERI 2005 = SIVERI Janoš: Raspuklina. Izbor. Novi Sad: Društvo književnika Vojvodine, 2005.

SzIVERI 2011 = Sziveri János müvei. Budapest: Gondolat, 2011.

THOмка 1987 = ThомкA Beáta: A Dia- s egyéb dalok margójára. In: SzIVERi János: Diadalok. Újvidék: Újvidéki Íróközösség, 1987. 91-94.

Tномка 1993 = Tномка Beáta: Áttetszö könyvtár. Pécs: Jelenkor, 1993.

ZALÁN 2000 = ZALÁN Tibor: Féreg kaparász a lélek falán. In: REMÉNYI József Tamás (szerk.): Barbár imák költője. Tanulmányok, kritikák, esszék Sziveri Jánosról. Budapest: Kortárs, 2000. 132-142.

ZIVLAK 2005 = ZivlaK Jovan: Ekstaza i drhtavica. Poezija Janoša Siverija. In: Siveri Janoš: Raspuklina. Izbor. Novi Sad: Društvo književnika Vojvodine, 2005. 47-52.

\section{ZOLTÁN VIRÁG}

Department of Hungarian Literature, Faculty of Humanities and Social Sciences, University of Szeged

\section{Space Modulations And Patterns of Matter (Reflections on the Poetry of János Sziveri)}

In this paper, János Sziveri's poetry is studied from the perspective of associative plays based on matter-grouping and landscape visions. There was a productive correspondence, as the poet himself underlined it, between him and Vasko Popa's works. The consonance between the book plans and the cycles of poems by Vasko Popa dedicated to the decomposition and recomposition of different matters and remains and the series of Sziveri's texts are secured by the stock of biological limitations and tactile sensations. The processes of focusing on different bodies and moving from body to body and the excess of neurotransmission as well as the desire for gratification are most efficiently distributed by the singular or plural first person. The Vasko Popa-esque radiation of life conditions extending beyond instrumentalized functioning and existence based on imitation echoes in Sziveri's landscape descriptions by intensifying the creative potential of fixed stance and mobility. 
The antipoetics and the cyclical planning of the texts of the Serbian author with some Romanian ancestors in his family tree were properly cultivated and elevated by his Hungarianspeaking companion.

Francis Ponge's art can be considered as their literary precursor. Almost anything that can be told about water, fauna, flora, and the natural cycle, about the sea, shells, snails, pebbles, bones, and oranges, is told in Le parti pris des choses (1942), Ponge's prose-poem cycle, which prevailed in the works of the well-informed Vasko Popa and, through Popa, in Sziveri's texts as well.

Sziveri's criticism of targeting the patterns of social viability of South-Eastern European repressive practices and collective false consciousness drowning in platitudes is accompanied by topographic scenery and ethnic diversity which accumulated landscape surfaces, fragments, and neighbourhoods framed by the Danube, Tisza, and Bega rivers as the scenes of geospecific identity. Comparing existential calculations, describing the shrinking of an ill body - these can be considered as a perceptual Pannonism of a subject observing and recording its direct impressions precisely and accurately.

Clinging onto the love of life, self-defence supplied by background knowledge about the countryside - as if all these were representing the escapist way of hiding, disguise, and diversion. Being doomed to live as an outcast, as a result of the status quo of regional coexistence officially prescribing homogeneity and of institutionalized incitement of feud, seems to be a dead certain conditioning of life. His attitude against any kind of quailing, his manner of shrugging off or making fun of regional fixed ideas and minority melodramas, bodily and linguistic 'Babylonization' coalesce into a polyphonic credo of a poet standing in the shade of wrecking and falling apart.

Keywords: minority literature, Yugoslavia, collectivity, identity, corporeality, sickness, geobiography, Pannonism

Open Access. This is an open-access article distributed under the terms of the Creative Commons Attribution 4.0 International License (https:/creativecommons.org/licenses/ by/4.0), which permits unrestricted use, distribution, and reproduction in any medium, provided the original author and source are credited, a link to the CC License is provided, and changes - if any - are indicated. (SID_1) 